\title{
El acto de crear, una ruta de acercamiento al psiquismo humano y de atención a la psicosis
}

\author{
The Act of Creation, an Approach Route \\ to the Human Psyche and the Psychosis Treatment
}

Noilin Molina Rojas

Priscilla Vargas Araya

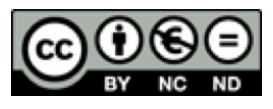

Esta obra está bajo una licencia Creative Commons Reconocimiento-No comercial-Sin Obra Derivada 


\title{
El acto de crear, una ruta de acercamiento al psiquismo humano y de atención a la psicosis
}

\author{
The Act of Creation, an Approach Route \\ to the Human Psyche and the Psychosis Treatment
}

\author{
Noilin Molina Rojas ${ }^{1}$ \\ Poder Judicial \\ Costa Rica \\ Priscilla Vargas Araya ${ }^{2}$ \\ Universidad de Costa Rica \\ Costa Rica
}

\begin{abstract}
Resumen
El presente escrito se desprende de un proyecto de atención psicológica a través del arte, con la participación de estudiantes, usuarios(as) de la Oficina de Bienestar y Salud (OBS) de la Sede Rodrigo Facio de la Universidad de Costa Rica. El proyecto buscó identificar los alcances de una propuesta de terapia que incorporaba la creación artística como mediación en el proceso terapéutico, a nivel a grupal para la clínica de estudiantes con diagnósticos asociados a las psicosis. El artículo ofrece una discusión sobre las implicaciones clínicas del acto creativo, el impacto terapéutico de los procesos grupales y el papel del acto creativo para la potencialización de habilidades o recursos personales. Los resultados se analizan a la luz de algunos de los aportes de la arteterapia y el Psicoanálisis.
\end{abstract}

Palabras clave: Terapia; arteterapia; psicosis; Psicoanálisis; creatividad

1 Psicóloga de Ambiente Laboral, Gestion Humana en el Poder Judicial. Máster en Psicología Clínica y de la Salud, por la Universidad de Costa Rica. Correo electrónico: nmolinar@poder-judicial.go.cr

2 Asesora Estudiantil, Unidad de Estudio y Asesoría de la Vicerrectoría de Vida Estudiantil, Universidad de Costa Rica (UCR). Máster en Psicología Clínica y de la Salud por la UCR. Correo electrónico priscila.vargasaraya@ucr.ac.cr

ESCENA. Revista de las artes, 2020, Vol. 79, Núm. 2 (enero-junio), 32-58 ISSN 2215-4906 
El acto de crear, una ruta de acercamiento al psiquismo humano

Artículos y de atención a la psicosis

\begin{abstract}
This paper is a result of the development of a mental health support project that was developed with the participation of a group of students of the University of Costa Rica, who had been diagnosed with a metal condition related to psychosis and who used the services of the "Oficina de Bienestar y Salud" (health and wellbeing office) of the Rodrigo Facio Campus. The project was implemented to identify the effects of an art therapy group intervention with this group of students. The article presents a discussion of the main clinical effects of the creative act, the therapeutic impacts of group therapy, and the role of the creative act on the abilities development process. The results are analyzed based on the contributions of art therapy and psychoanalysis.
\end{abstract}

Key words: Therapy; art therapy; psychosis; psychoanalysis; creativity

ESCENA. Revista de las artes, 2020, Vol. 79, Núm. 2 (enero-junio), pp. 32-58 


\title{
Introducción
}

\author{
"No es quizá inútil, hacer notar que una de las cosas \\ más bellas de los pintores de nuestro siglo ha sido pintar \\ la oscuridad que es así mismo color"
}

Van Gogh (2003, p. 155)

Tras la muerte del padre de Van Gogh en 1885, este pintor se sumergió en sus estancias más sombrías y lúgubres, enfrentó cara a cara el dolor de la pérdida y de la ausencia. Fue en este punto de su existencia, en que su creación artística logró hacer visible los matices, las luces y los colores, aquellos propios de las zonas en donde la luz jamás alcanza, principalmente visible en su obra "Los comederos de patatas" (1885).

Imagen 1. Los comederos de patatas, 1885.

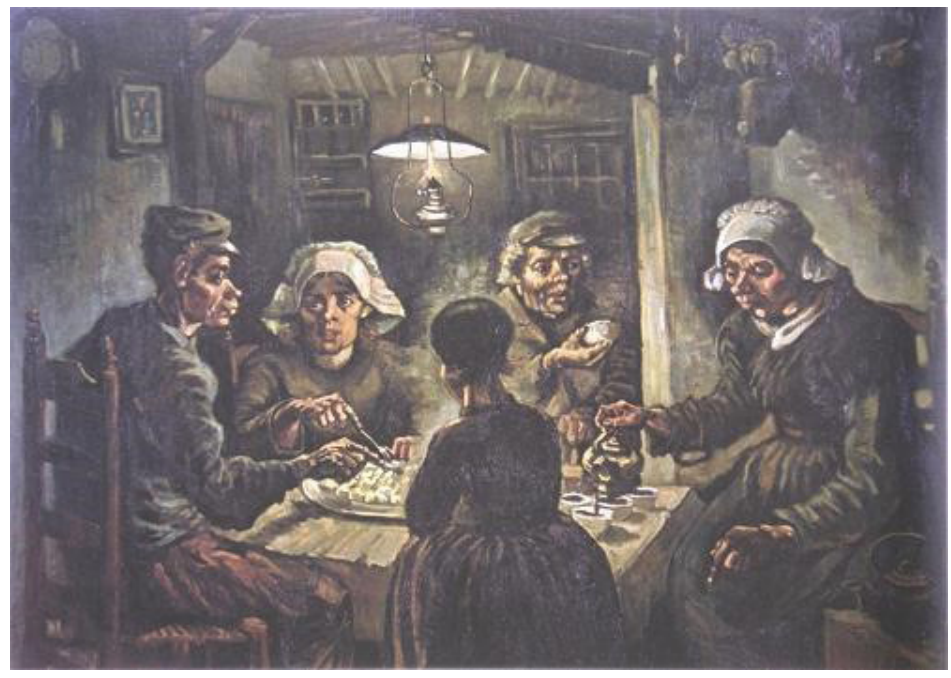

Fuente: Vincent Van Gogh (1985) citado en Domínguez (2004).
"Pintar la oscuridad que es así mismo color" es la metáfora que ha inspirado la profundización de los impactos que tiene el proceso de crear dentro del psiquismo humano. Cuando se crea, el o la artista logra dar vida a las ausencias, puede crear en el vacío, reconstruye historias, elabora nuevos pasajes e inventa nuevos mundos. Esta posibilidad que da el acto de crear lleva a pensar ¿qué pinta?, ¿qué esculpe?, ¿qué diseña un artista, sino algo de lo que se juega en su mundo?, ¿de dónde toma las imágenes, las ideas, sino de su universo psíquico?, ¿no será acaso, que en cada producción ar-

tística hay trazos y trozos del artista, de los otros, de los recuerdos e, incluso, de aquello que quizá no recuerda?

El vínculo de la creación y el psiquismo humano crea un puente que vincula el acto creativo con procesos psíquicos profundos que, desde posicionamientos psicoanalíticos, principalmente los desarrollados por Kolko (2011), podría constituirse una vía para la elaboración clínica. En este sentido, el acto creativo implica una escritura, en el caso de la plástica, cada obra es un texto en un lenguaje no verbal, que materializa una historia inspirada en impresiones, sensaciones, emociones y recuerdos. La posibilidad que abre el acto de 
crear suscitó la interrogante de si el acto creativo como recurso de mediación terapéutica podría ofrecer una vía alterna que permitiera crear y plasmar, en lo concreto, aquello que en el orden de la palabra el sujeto no ha logrado expresar. Lo anterior favorecería una ruta terapéutica para aquellos sujetos con estructuración psicótica, dado que, por sus particularidades, la palabra por sí misma, puede tornarse insuficiente.

Entre los principales postulados de la Kolko (2011), se encuentra la consideración de que en la clínica de la psicosis se apuesta por la re-creación de los significantes marginales de las historias de vida de los sujetos psicóticos, como suplemento a la falla en la instauración de la Ley del Nombre del Padre. Esta falla impide al sujeto lograr un proceso de individuación, lo cual implica una suerte de atrapamiento. La hendidura en la instauración del significante Nombre del Padre imposibilita la inscripción de la cadena significante y, por tanto, se habla de una falla en el universo simbólico. Con base en la propuesta lacaniana, la clínica de la psicosis busca el tejido o creación de significantes marginales de sus propias historias (Kolko, 2011). Con base en lo anterior, se propuso la creación de un espacio de atención terapéutica mediada por el arte, en el marco de esta clínica que busca re-crear los faltantes de sus historias, como una forma de suplemento, que permita al sujeto mantenerse en estructuración. Para ello, se creó un espacio de atención grupal, desde la arteterapia creativo expresiva unimodal, con estudiantes activos y activas, que presentaran diagnósticos asociados a la psicosis.

Es así como el presente artículo se propone reflexionar sobre al acto creativo como una vía de acceso al psiquismo y como mediación terapéutica para la atención de personas en condición de psicosis. Para ello, se presenta una síntesis teórica y algunos hitos que permitieron la vinculación del acto creativo con el psiquismo humano hasta la consolidación de la arteterapia como disciplina terapéutica. Asimismo, se expone una síntesis metodológica del proyecto y las principales reflexiones que se desprenden de la investigación realizada en el 2017, titulada "Una experiencia arteterapéutica con estudiantes de la Universidad de Costa Rica: diálogos entre la Arteterapia, el Psicoanálisis y las psicosis”, realizada por las autoras, en el marco de la Maestría en Psicología Clínica y de la Salud de la Universidad de Costa Rica, a partir de la cual se reflexionará sobre esta posibilidad que abre el proceso creador en el arte. Es importante señalar que, además de las reflexiones, en este documento se muestran algunos de los trabajos realizados por los y las participantes, estos serán expuestos con los seudónimos con que se presentaron los resultados de la investigación, lo anterior como parte del compromiso de confidencialidad y protección para los y las estudiantes. 


\section{Las creaciones artísticas y el psiquismo del artista}

El vínculo entre la creación artística y el universo psíquico del o de la creadora abre un puente fundamental para quienes trabajan con el psiquismo humano, pues ofrece una posibilidad de entender el acto creativo como una vía alterna para llegar al mundo psíquico de los seres humanos. Tradicionalmente, la Psicología y, fundamentalmente, el Psicoanálisis, parten del lenguaje como el eje estructurante del psiquismo humano y, mediante él, la vía de acceso al universo inconsciente. No obstante, la creación artística se consolida como un puente que permite transitar por el mundo psíquico de su creador, recorriendo sus vivencias, sus dolores o faltas, pero no necesariamente desde la palabra, sino desde otro lenguaje, uno que parte de imágenes y colores, significantes que finalmente encarnan un sentido, que de manera consciente o inconsciente, pertenecen al artista que los creó.

Este posicionamiento del arte como una vía de acceso al mundo psíquico de su creador o creadora, parte también de la posibilidad que da el acto creativo al sujeto, para que este conecte con su mundo interno, lo que implica varios movimientos sustantivos. Estos movimientos, en primera instancia, requieren una inmersión en sus impresiones, emociones, pensamientos y recuerdos para, posteriormente, circunscribir ese océano de imágenes mentales y organizarlos en una composición de símbolos con un borde o límite que le permita volcarlo en un lienzo -en el caso de la pintura-. Seguidamente, se podrá crear un texto en un lenguaje no verbal, sino visual, el cual, finalmente, será mostrado al público (espectadores) su creación. El acto de crear como movilizador del psiquismo humano ha ido alimentándose de diversas tradiciones y de diversos momentos de la historia, latitudes y contextos. A continuación, se presenta un extracto de los principales hitos identificados.

\section{Recorrido por el arte y sus impactos en el psiquismo humano}

Históricamente, el arte ha jugado un rol mediador entre el ser humano y las interrogantes de orden universal, en tanto medio de expresión y creación de tentativas de respuestas. Si bien, sus orígenes son inherentes al ser humano, la creación del arte como terapia puede remontarse al siglo XIX, cuando fue reconocida como disciplina terapéutica. Antes de su consolidación como tal, se repasarán los principales hitos que fueron colocando al arte como un intermediario con el universo psíquico de los y las artistas:

1. En la Antigüedad, el arte fue puesto al servicio de la cura como un modo de catarsis (Martínez, 2004, pp. 37-56).

2. La psiquiatría se interesó en la producción artística de las y los "locos" y su valor psicopatológico, al igual que los y las artistas se interesaron en dichas producciones por su valor artístico (Martínez, 2004, pp. 37-56). 
3. El Humanismo introdujo cambios en la educación, los cuales incorporaron el valor del arte y la creatividad como elementos básicos de autorrealización. Desde esta visión, el foco debe estar en los procesos creativos y no en los resultados plásticos, con lo cual las habilidades artísticas específicas pierden protagonismo y el arte deviene una praxis para todas y todos (Reyes, 2011).

4. Influencia del pensamiento romántico en el arte, lo cual situó el énfasis en los sentimientos, la sensibilidad y la libertad de la creación artística y facilitó la incorporación de prácticas artísticas en el espacio terapéutico (Reyes, 2011, pp. 110-111).

5. Dominio del Psicoanálisis sobre el arte y práctica artística a nivel terapéutico. El planteamiento del inconsciente, los mecanismos de proyección y sublimación, funcionaron como referentes para el uso de la imagen como comunicación simbólica en un contexto terapéutico, que condensa el uso del lenguaje y la creatividad como aspectos centrales (Reyes, 2011, pp. 112-117).

6. Utilización del teatro para el tratamiento de las y los "enfermos mentales". De acuerdo con Martínez (2004), algunos autores señalan al Marqués de Sade como un precursor del movimiento arteterapéutico, pues a comienzos del siglo XIX promovió el teatro como modo de expresión y medio para que los "enfermos" salieran de su estado. Entre 1803 y 1813, se dirigían espectáculos mensuales en la casa de salud de Charenton, con representaciones públicas. A finales del siglo XIX, el teatro fue recomendado para aquellas personas consideradas "enfermas mentales" porque les permitía salir de su "apatía y repliegue delirante de su mundo interior" (Martínez, 2004, p. 45), al igual que el piano, el billar y el dominó. La utilización de estos recursos en diversas casas de salud se fue expandiendo y se establecieron alianzas entre médicos y artistas. Además, la Psiquiatría empezó a dar cabida al arte como parte de sus tratamientos. En este mismo siglo, el arte empezó a formar parte de otras disciplinas como la terapia ocupacional, por lo que se comenzó a recomendar como medio de recuperación e integración a la sociedad.

7. Interés de la Psiquiatría por el arte de las y los locos. Siguiendo a Martínez (2004), en este mismo periodo, cobró fuerza el interés por el contenido de las producciones (dibujo y pinturas) de las y los "enfermos mentales" y empezaron a identificar tipologías de las creaciones, de los síntomas y de los padecimientos. En este sentido, surgió un interés de parte de la Psiquiatría por la producción plástica de las y los pacientes, por lo que se avocaron a su estudio y colección. En esta línea, destaca el trabajo del Dr. Hans Prinzhorn, psiquiatra, historiador del arte, músico y filósofo, quien en 1922 publicó en Alemania "Expresiones de la locura", colección que reunía obras de internos de psiquiátricos de varios países de Europa y 
englobaba: dibujos, pinturas, esculturas en madera, collage, bordados, objetos de tela y fotografías de tatuajes, objetos o arquitecturas fantásticas.

\section{Consolidación de la terapia mediada por el arte como disciplina terapéutica}

Fue en los Estados Unidos (EEUU) e Inglaterra donde se encontraron las y los pioneros en los estudios de la arteterapia como disciplina. En EEUU se consolidó como profesión en la década de 1930, con exponentes como Margaret Naumburg, Edith Kramer y Florence Cane. En el Reino Unido comenzó en 1938 con el pintor Adrian Hill, quien logró sistematizar su vivencia de cómo el arte le ayudó en su proceso de enfermedad y hospitalización (Martinez, 2004). Para mediados del siglo XX se empezaron a consolidar propuestas de formación específicamente en arteterapia. En este punto destaca Marie Pétrie con su obra Art and Regeneration en 1946 (citado en Reyes, 2011, pp. 112-117), quien introdujo elementos de la formación requeridas en arteterapia. Durante este mismo año en el Reino Unido, se contrató en el Hospital de Netherne al primer arteterapeuta de la historia: Eduard Adamson (Reyes 2011).

En 1947, se publicó en EEUU el estudio Free Art Expression of Behaviour Disturbed Children as a Means of Diagnosis and Therapy de Margaret Nauburg (citado en Reyes, 2011, pp. 112-117), este propuso que tanto padres, educadores y psiquiatras debían reconocer la liberación del inconsciente en las proyecciones artísticas espontáneas e imaginativas de los niños y niñas. Nauburg (1947) situó la importancia en la imagen y en el proceso de creación como parte del proceso psíquico individual de cada sujeto, como canal de expresión inconsciente. Ella enfatizó la importancia de ajustarse al ritmo del paciente, de realizar primero un desbloqueo creativo, saber ver y escuchar.

Otra pionera que merece mención es Edith Kramer, quien se dedicó a desarrollar de manera sistemática el valor de la creación artística como terapia. Su trabajo se centró en la activación de procesos psíquicos durante la creación y no en la interpretación de estos. A dicha autora le interesó observar como "Ios conflictos pueden ser trasladados a través de la creatividad de sus estrechos confines de la vida personal, al amplio mundo de la imaginación y la aventura" (Reyes, 2011, p. 37). La autora enfatiza en el potencial de actividad creativa como medio de transformación, de desmantelar fantasías y de su habilidad para preservarlas. Ella distingue actividades artísticas que pueden sublimar la energía agresiva y trabajar las emociones regresivas.

En 1949, se creó en Francia la Compagnie de l'art brut, impulsada por Jean Dubuffet, artista que nombró así, a aquellas manifestaciones artísticas contraculturales, principalmente realizadas por pacientes de hospitales psiquiátricos. Señala que buscaba "investigar aquellas producciones artísticas realizadas por personas oscuras y que presentan una 
forma de invención personal, de espontaneidad, de libertad, más allá de convenciones y hábitos recibidos" (Reyes, 2011, p. 34).

Finalmente, cabe mencionar que, en 1959, se creó la SIPE (Société Internacional de Psychopathologie de l'Expression) en Francia, en 1961 se fundó la revista American Journal of Art Therapy, y en 1964 la Brittish Association of Art Therapists. En 1973 se creó el Museo das Imagens do inconsciente en el Centro Psiquiátrico Nacional de Río de Janeiro, y en 1999 se introdujo como un estatus profesional en Gran Bretaña. La evolución y expansión de la arteterapia se mantiene hasta hoy, no obstante los acontecimientos citados son aquellos que abrieron camino a la disciplina arteterapéutica, trabajos pioneros que permitieron consolidarla como la conocemos hoy día.

\section{La arteterapia expresiva y su propuesta terapéutica}

La arteterapia expresiva es una modalidad terapéutica que utiliza técnicas plásticas como el dibujo, pintura, collage y escultura para favorecer en el sujeto la expresión, concreción y visualización de las emociones y/o conflictos internos. En este sentido, el producto final o su técnica no son determinantes, como sí lo es el proceso creativo. A continuación, se realizará un repaso por las premisas centrales de la propuesta arteterapéutica:

\section{El proceso creativo constituye un medio de expresión no verbal, por tanto, trasciende a la palabra}

El proceso de creación artística es una vía mediante la cual el sujeto logra plasmar elementos que generalmente no son alcanzados por el lenguaje verbal. En este, la persona logra crear aquello del orden de la ausencia, lo que no está, que escapa a la palabra pero que le pertenece, que le atraviesa y le determina. Podría plantearse que es una escritura desde la imagen. Martínez (2004), de manera poética, lo explica de la siguiente manera:

Y las personas seguimos necesitando ver obras de arte, y sentir que desde ella se nos convoca a lo que ya no está, a lo que otro ha visto y ha sentido, a la búsqueda y al encuentro, a lo común que compartimos y a lo intransferible de cada uno de nosotros, y cómo también se nos convoca a la ausencia, y a algo que, a veces, es impronunciable. Por ello, la palabra nunca pretendiera sustituir el trazo (p. 16).

El proceso creativo implica crear en el vacío, crear la nada, construir imágenes mediante un proceso de destrucción y creación, de encierro y liberación constante. El sujeto logra crear como una función liberadora, como lenguaje que comunica a los otros, pero, sobre todo, a sí mismo, es un puente, una cocedura que conecta partes de sí. El efecto terapéutico en arteterapia no se deriva de los intercambios verbales alrededor de la obra, sino 
que sitúa su énfasis en el valor y las posibilidades que se juegan en el proceso creador, por la posibilidad de sublimar, de organizar metafóricamente elementos, en la posibilidad que el sujeto encuentre y elabore un universo de imágenes significantes de sus conflictos subjetivos. Es decir, desde este posicionamiento, el acto creativo implica una serie de movimientos psíquicos que pueden ser terapéuticos per se porque en el acto de crear se trasciende a la palabra, se representa, se re-crea, se construye aquello que escapa al lenguaje verbal. En palabras de Schaverien (1989, citado en López, 2006) ninguna pintura puede ser explicada totalmente a través de la palabra; si así fuera, no se tendría necesidad de hacerla. Es decir, la obra creada encarna dimensiones de expresión que no pasan por la palabra y que se activan con el proceso creativo.

\section{El acto creativo tiene un lugar privilegiado en el proceso terapéutico}

La arteterapia expresiva fundamenta su impacto terapéutico en el acto subjetivo de crear, por ello, la técnica y la estética de la obra pasan a un segundo plano. El efecto terapéutico no se basa en el resultado o su interpretación -la interpretación queda reservada a otras tradiciones epistémicas-, sino que se basa en los movimientos psíquicos que implica el acto de crear en el sujeto. Para crear, el sujeto debe sumergirse en su universo valorativo, en sus imágenes, en sus recuerdos -que son imágenes-, en sus emociones, en sus vacíos y ausencias, como un momento contemplativo para poder crear. Por ello, el proceso arteterapeútico abre la posibilidad de organizar metafóricamente. El acto de creación artística permite a las personas acceder de forma profunda, como una vía para la conexión con su mundo emocional, de manera que, al trabajar y transformar la obra, se abre la posibilidad de transformar los componentes afectivos asociados a esta.

Para Polo (2000) por medio de las imágenes, es posible simbolizar sentimientos y experiencias de manera más efectiva que a través de la palabra: "la actividad artística proporciona un medio concreto -no verbal- a través del cual la persona puede lograr una expresión, al mismo tiempo, consciente e inconsciente y que puede emplearse como valioso agente de cambio terapéutico" (Dalley, citado en Polo, 2000, p. 313). En esta cita, el autor añade un elemento importante asociado al nivel de consciencia que el sujeto puede tener sobre sus transformaciones. En este sentido, los cambios terapéuticos pueden presentarse aún cuando el sujeto no tome consciencia del movimiento, es decir, en el acto creativo pueden ocurrir modificaciones o movilizaciones psíquicas, conscientes o inconscientes. 


\section{El proceso terapéutico es un espacio para la libertad y de cuestionamiento del lugar tradicional del terapeuta}

El proceso arteterapeútico implica dejar actuar al sujeto, conlleva momentos de contemplación y reflexión, anidado en un espacio suspendido en las emociones que emergen. Requiere de un acompañamiento al que crea y de escucha ante la afloración de lo visible y de lo impalpable. Siguiendo a Coll (2004), este proceso involucra el despliegue de un tiempo creador y reflexivo, un tiempo estético donde se funden las emociones, las experiencias, la necesidad de saber de uno y de saber del mundo. Un tiempo marcado por la creación, que articula la repetición, tanto aquella sintomática y como la reparadora.

Las imágenes creadas por la persona involucrada son extensiones de sí misma, por lo que no se actúa de manera interpretativa, adivinatoria, ni se propone un guión con preguntas, sino se promueve la apertura y el respeto hacia la persona. Lo anterior, en un marco de libertad para que encuentre sus límites y sus capacidades, sus conflictos, sus estructuras de repetición y sus bloqueos, y poco a poco se comprenda, se reconozca, se admita, y sin prosa, construya otros puntos de vista (Coll, 2004). En este sentido, las imágenes pertenecientes al ser que las crea son documentos de vida y deben ser tratados como su vida y hablados por el sujeto que los realiza, en su singularidad, drama y/o grandiosidad y no a través de interpretaciones que limiten su propia producción.

El proceso arteterapéutico busca la veracidad y la proximidad con una o uno mismo, con lo que se plantean búsquedas y caminos que solo el sujeto -acompañado de la figura de terapeuta- será capaz de encontrar. Es un espacio de encuentro, de interrogación y es, siempre, una respuesta inacabada. El lugar del terapeuta es el de un acompañante, testigo, escucha, continente, no interpreta, sino que brinda un marco de seguridad para que el sujeto pueda escudriñar y descubrir aquello que ha creado y pueda entenderlo en el marco de su historia.

\section{Ruta metodológica}

El proyecto, de cuyos resultados nutren la presente reflexión, nace a partir de la pregunta por la vida de estudiantes universitarios que han sido diagnosticados con un trastorno asociado a la psicosis, que deben enfrentar las complejidades de su condición y las luchas continuas por resistir ante las presiones del sistema educativo formal. En este contexto, al estar inmersas en la atención clínica emocional de estudiantes en la Universidad de Costa Rica (UCR) y, por ende, familiarizadas con población estudiantil en condición de vulnerabilidad psíquica, nació el reto como investigadoras, de reflexionar sobre las posibilidades terapéuticas del acto creativo en la atención de jóvenes estudiantes de esta universidad que contaran con diagnósticos asociados a las psicosis. Para ello, se conjugaron los 
aportes del Psicoanálisis a la clínica de las psicosis y los de la Arteterapia como modalidad terapéutica. La investigación además se fundamentó en una visión de la universidad como una institución que tiene un compromiso con la calidad de vida y con la permanencia de aquellas personas a quienes abre sus puertas.

De esta forma, para plantear el estudio se consideraron aspectos medulares del Psicoanálisis lacaniano, ya que ha pretendido aproximarse a la comprensión de la psicosis, sosteniendo que su génesis ocurre a partir de una falla en los procesos de integración subjetiva, lo que provoca que el sujeto permanezca en una suerte de desintegración. Dicha desintegración trae como consecuencia una caída de la capacidad de simbolizar y de metaforizar. Es decir, desde los planteamientos psicoanalíticos lacanianos, el sujeto psicótico pierde la posibilidad de organizar en recuerdos muchos de sus acontecimientos y percepciones, entonces dichos recuerdos quedan desorganizados o excluidos de la experiencia subjetiva (Marini, 1989). Para la clínica psicoanalítica lacaniana, el quehacer clínico se ocupa de acompañar al sujeto en su búsqueda de conexiones o coceduras en su experiencia subjetiva, que le permitan acceder a un proceso más integrador y dar nombre a aquello que ha permanecido al margen de sus historias, que no se pudo reconocer como parte de su experiencia (Kolko, 2001).

Es desde el anterior posicionamiento clínico que se plateó la posibilidad de sumar la experiencia y aportes de la Arteterapia en la investigación y, específicamente, del acto creativo, como un posible espacio para la reescritura de los significantes ausentes o marginales en la experiencia de las y los jóvenes en atención. Es así como se vislumbró la Arteterapia como vía para la construcción o creación de las ausencias simbólicas, mediante un lenguaje no verbal, que permitiera resarcir los faltantes en la historia del sujeto, en tanto parches o costuras subjetivas. De esta forma, surge la pregunta de si el acto creativo como recurso terapéutico puede ofrecer una vía alternativa para la reconstrucción de las historias de los sujetos, la búsqueda de los significantes marginales y que, a través de su mediación, pudiera conducir a la palabra y, con ello, abriera la posibilidad de la inscripción de dichos significantes. Con base en estas reflexiones anteriores, surgió la interrogante de si el favorecimiento de un espacio psicoterapeútico, con aportes de la Arteterapia y el Psicoanálisis, con personas con una vía de estructuración subjetiva psicótica, podría ser un recurso efectivo para la atención clínica de estos sujetos. Esta pregunta se sintetizó de la siguiente forma: ¿cuáles son los principales aportes de una propuesta arteterapéutica grupal en la intervención clínica de estudiantes con un diagnóstico asociado a la psicosis?

Para la selección de participantes se consideraron estudiantes activas o activos de la UCR, que hubiesen recibido atención por el área de Psicología o la especialidad Psiquiatría de la Oficina de Bienestar y Salud (OBS) y que contaran con alguna categoría diagnóstica 
de la Psiquiatría o Piscología clínica, que por su psicodinamia, podría incluirse dentro del tipo de estructuración psicótica. Además, se consideró que tuvieran anuencia e interés en la modalidad terapéutica propuesta. Adicionalmente, los criterios de exclusión planteados correspondieron a la presencia de un brote psicótico durante la entrevista preliminar o al inicio del proceso arte terapéutico, o que se asistiera a la entrevista inicial o las sesiones arteterapéuticas en condición de ebriedad o con cuadros asociados al consumo de drogas ilícitas. La muestra del proyecto estuvo conformada inicialmente por siete participantes, en la tercera sesión se tuvo una baja y continuaron el proceso las seis personas restantes. Como medida de protección ética a las y los jóvenes participantes, se usó un consentimiento informado y se ofreció la posibilidad de coordinar la atención en los servicios de Psicología y Psiquiatría de la OBS, en caso de que se presentara alguna necesidad particular durante la participación en el proceso.

El proyecto se basó en el tipo de intervención de Arteterapia creativa expresiva unimodal, lo que implica que se utilizaron únicamente técnicas de la plástica, no así de otras corrientes creativas como la danza o la musicoterapia. En esta línea, se recurrió a recursos plásticos con distintas características y finalidades, entre las que se pueden mencionar materiales para dar soporte, tales como el cartón y cartulina; medios gráficos, entre los que se encontraban tizas pastel, marcadores, pinturas y crayolas; para trabajos tridimensionales, como las esculturas de arcilla y plastilina, y otros materiales, como por ejemplo estereofón, revistas, madera, materiales de desecho, escarcha, hojas, otros (Marxen, 2011).

Los materiales fueron aportados por las terapeutas, pero se mantuvo la apertura de que si las y los jóvenes participantes deseaban llevar algún material de reciclaje, pudieran hacerlo. En cada sesión se fueron incluyendo materiales nuevos para buscar la posibilidad de que se utilizara algún recurso novedoso, que favoreciera el proceso creativo y expresivo de las y los estudiantes. Cabe destacar que dentro de este marco, se respetó en todo momento la creatividad y libertad de las y los jóvenes para el uso de materiales y el desarrollo del proyecto de cada sesión.

Se realizó un total de 10 sesiones de cuatro horas de duración, con una regularidad de una vez a la semana. Cada sesión estuvo estructurada en tres momentos, que buscaban dar fluidez y seguridad a la dinámica de grupo, por ello se contó con una bienvenida, encuadre, actividad de sensibilización creativa. Luego se procedió a realizar las actividades centrales de expresión creativa y, finalmente, se dio pie a un cierre de cada sesión. A continuación, se describe brevemente cada parte de las sesiones: 


\section{Bienvenida, encuadre y sensibilización:}

En este primer momento, se realizó una inducción al proceso y actividades de sensibilización al acto creativo ${ }^{3}$. A partir de la segunda sesión se introdujo la realización de un recuento de lo abordado en las sesiones anteriores, para dar continuidad al proceso, asimismo se presentaba el tema elegido para cada sesión y las opciones de trabajos del día correspondiente. Para la séptima sesión se incluyó un espacio inicial para compartir libremente, el curso de la semana, este espacio surgió de manera natural en el grupo y fue respaldado por el equipo terapéutico. En este, se intercambiaban las experiencias de los días previos a la sesión, lo que facilitaba la expresión verbal de emociones y pensamientos, fortalecía el vínculo grupal, y aportaba mayor claridad sobre los objetivos planteados para las sesiones.

\section{Actividad de expresión creativa central:}

En este momento de la sesión, se exponían las propuestas temáticas y proyectos específicos sugeridos por las terapeutas. A partir de la segunda sesión, el grupo comenzó a sugerir los temas siguientes. Para todas las actividades artísticas se ofreció plena libertad de escogencia de los materiales a utilizar y se brindó el acompañamiento constante de ambas integrantes del equipo arte terapéutico.

\section{Actividad de cierre de la sesión:}

Al final de cada sesión, se realizó una puesta en común de los trabajos y las movilizaciones emocionales que implicó su elaboración. La decisión al respecto de compartir sus producciones y sentimientos siempre fue voluntaria. Cabe mencionar que en todas las sesiones, todas y todos los participantes mostraron receptividad a las intervenciones del grupo. Este espacio fue fundamental, pues incentivó la expresión emocional, el repaso y reconstrucción de las historias de vida y el compartir grupal a partir de las experiencias y aprendizajes de cada joven.

\section{Refrigerio:}

Si bien el refrigerio no ocupó un espacio definido durante las sesiones, se incluyó para que estuviera disponible durante toda la sesión, de modo que cada participante podía disponer de este, en el momento que lo deseara. Se menciona, ya que fue evidente que este funcionó para fortalecer la confianza en la dinámica grupal y en las terapeutas, elementos transferenciales que se tornan imprescindibles para el trabajo con personas que viven condiciones de sufrimiento profundo.

${ }^{3}$ Luego de la tercera sesión, se decidió prescindir de las actividades de sensibilización, ya que el grupo presentaba una alta disposición y sensibilidad al acto creativo.

ESCENA. Revista de las artes, 2020, Vol. 79, Núm. 2 (enero-junio), pp. 32-58 
El acto de crear, una ruta de acercamiento al psiquismo humano

Artículos y de atención a la psicosis

Los temas de las sesiones fueron el resultado de los aportes del grupo y de lo observado por el equipo terapéutico durante el proceso, a continuación se sintetizan en el siguiente cuadro:

Cuadro 1. Temáticas de las sesiones del proyecto

\begin{tabular}{|l|c|}
\hline \multicolumn{1}{|c|}{ Tema } & Número de sesión \\
\hline Presentación ¿Quién soy?: & Sesión 1 y 2 \\
\hline Las dificultades en el camino de mi vida & Sesión 3 \\
\hline Experiencias que aún causan dolor y los avances o logros alcanzados & Sesión 4 \\
\hline Dinámica e historia familiar & Sesión 5 \\
\hline La reinvención de sí: apropiándose de los anhelos y los sueños & Sesión 6 \\
\hline La reinvención de sí: apropiándose & Sesión 7 \\
\hline
\end{tabular}

Fuente: elaboración propia.

De esta forma, la primera sesión tuvo como énfasis el inicio del proceso y de integración grupal, el desarrollo de la alianza terapéutica y la ampliación de la información a las y los participantes del proyecto. De la segunda a la octava sesión, el énfasis estuvo situado en el trabajo clínico de diversos temas de fondo mediante la expresión plástica. La novena y décima sesión se dedicaron al cierre del proceso, aunque este se comenzó a trabajar desde la quinta sesión, previendo que, por las características emocionales de los y las participantes, era necesario cuidar el impacto que pudiera tener el cierre del proceso en cada persona.

Con el fin de evaluar el desarrollo del proceso, se utilizó una metodología cualitativa de evaluación compuesta por diversos insumos, entre los que se encuentran un cuestionario elaborado por las terapeutas que buscó valorar la percepción de salud pre y post desarrollo del proyecto, tres preguntas de evaluación que fueron aplicadas al cierre de cada sesión y un mural de realimentación que estuvo abierto durante las sesiones.

ESCENA. Revista de las artes, 2020, Vol. 79, Núm. 2 (enero-junio), pp. 32-58 
Noilin Molina Rojas

Artículos

Priscilla Vargas Araya

\title{
Reflexiones sobre los alcances del arte como mediación terapéutica en personas en condición asociada a la psicosis
}

\author{
¿Sobre qué huellas puede construirse lo que jamás ha \\ sido representado por un sujeto, lo que jamás ha \\ sido hablado, pensado, y que sin embargo, viene a \\ mostrase en un acto, un delirio, y mejor aún en una \\ producción artística? ...
}

yo los considero a los dos como producciones que se orientan a representar lo irrepresentable

(Kolko, 2001, p. 9).

En este apartado se presenta una discusión de las principales conclusiones del equipo de investigación referentes a los beneficios del acto creativo para el trabajo con jóvenes con diagnóstico de psicosis. La experiencia de este proyecto permite sostener que el proceso arteterapéutico grupal tuvo implicaciones terapéuticas fundamentales para su tratamiento. Los principales aportes de la experiencia se relacionan con las implicaciones clínicas del acto creativo con el impacto terapéutico profundo de los procesos grupales y con el papel del acto creativo como un recurso para la potencialización de habilidades en las personas.

\section{Implicaciones clínicas del acto creativo}

A partir de los hallazgos del proyecto, se sostiene que el acto creativo puede fungir como una vía mediadora de la palabra, que permite reconstruir historias, crear o re-crear los ausentes y/o aspectos marginales de las historias de la persona sufriente. El acto creativo, en este contexto, viene a constituirse en un puente que permite unir el universo de imágenes, recuerdos y sensaciones con la materialidad de la obra plástica. Y esta, a su vez, permite la construcción de palabras, como un nexo significante para la inscripción simbólica de elementos faltantes en las historias. El acto creativo implica una escritura; en el caso de la plástica, cada obra es un texto en un lenguaje no verbal que materializa una historia. En cada obra, el sujeto escribe un guión, formulando una respuesta tentativa a una pregunta formulada por las terapeutas, la cual busca dar un sentido al enigma que le supone el discurso delirante.

El impacto terapéutico del proceso creativo es profundo, pues le implica al sujeto, en primer lugar, sumergirse en sus impresiones, emociones, pensamientos y recuerdos como un proceso introspectivo, que le demanda conectar consigo mismo. Además, le faculta

ESCENA. Revista de las artes, 2020, Vol. 79, Núm. 2 (enero-junio), pp. 32-58 
para organizar los pensamientos, las emociones, los recuerdos y las impresiones, lo cual implica una especie de circunscripción o trazado de borde, que favorece los procesos de concreción del pensamiento. También, posibilita la creación de un texto, en este caso, a través de obras plásticas, como respuesta a la pregunta formulada por la figura terapéutica para finalmente mostrar al grupo y apalabrar aquello creado en la obra y, por tanto, permite la inscripción en el lenguaje. Dicha inscripción implica, en primera instancia, la creación en la plástica, seguido de un apalabramiento en donde se le presenta al otro lo trabajado (lo vivido o sentido). Al final, se abre la posibilidad de acompañar al proceso de reconstrucción histórica, con la escritura de un texto, cual artificio literario que permita la construcción de un guión suplementario de su vida.

La palabra escrita tiene un peso fundamental en el proceso, pues es una vía que permite consolidar la llamada inscripción simbólica. En este punto, es importante aclarar que para la Arteterapia expresiva, el pasaje a la palabra no es indispensable para los impactos terapéuticos. No obstante, en este punto nos distanciamos de los planteamientos arteterapeúticos ortodoxos, en términos de la importancia que tiene para nosotras como investigadoras y terapeutas, el peso de la palabra. La puesta en palabras y la escritura como ejercicio de creación fueron vitales para el proceso terapéutico. El impacto del acto creativo viene a ser la posibilidad de mediar, de hacer puente, de crear conexiones entre recuerdos y emociones con las palabras. Por ello, destacamos el valor clínico del acto creativo en la psicosis, como un medio que favorece los procesos de concreción del pensamiento. Como reseñamos, la materialidad que implica una obra plástica, permite no solo plasmar pensamientos y emociones, sino que brinda la posibilidad de regresar a ello. Lo anterior, conlleva al trazado de una especie de borde para el sujeto, que ponga límite al rebalse de pensamientos o sentimientos que puede experimentar.

El rebalse o desorganización del pensamiento queda ejemplificado con el primer trabajo de uno de los participantes, quien realizó un autorretrato (ver figura 2), enfatizando la desorganización de pensamientos y la sobredimensión que tienen estos en su vida. Es importante destacar que en la décima sesión, este mismo participante creó un trabajo (ver figura 3), en el cual logró integrar diferentes componentes de su vida, refirió que su mente seguía siendo importante pero no el eje central. Se identificó un esfuerzo pictórico por ubicar los distintos planos de su existencia, con mayor integración y estructura. A continuación se presentan las figuras. 
Imagen 2. Autorretatro

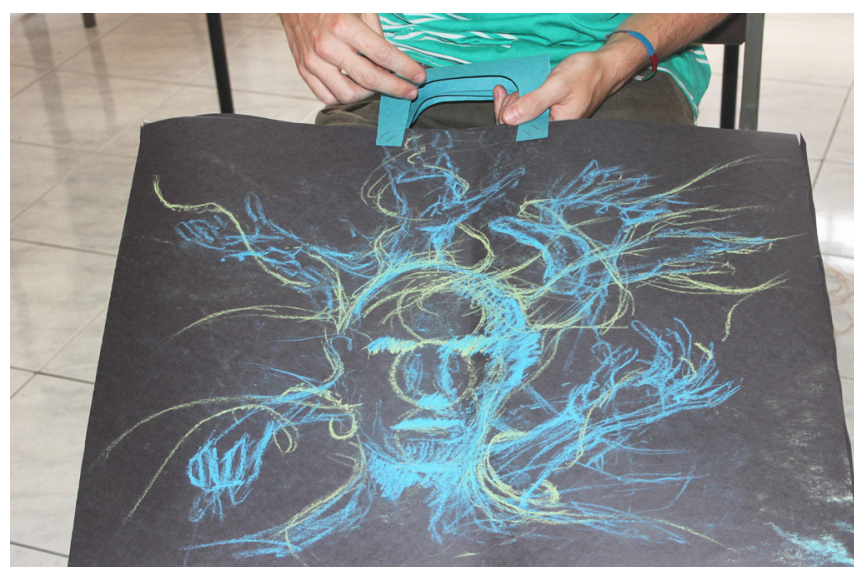

Fuente: elaborado por D, tomado de Molina y Vargas (2017, p.84)

Con respecto a lo anterior, la creación como un elemento estructurante y de puesta de límites a su pensamiento fue enfatizado por las y los jóvenes a partir de diversas formas y momentos del proceso. Al respecto, mencionaron lo siguiente:
Imagen 3. Altar personal

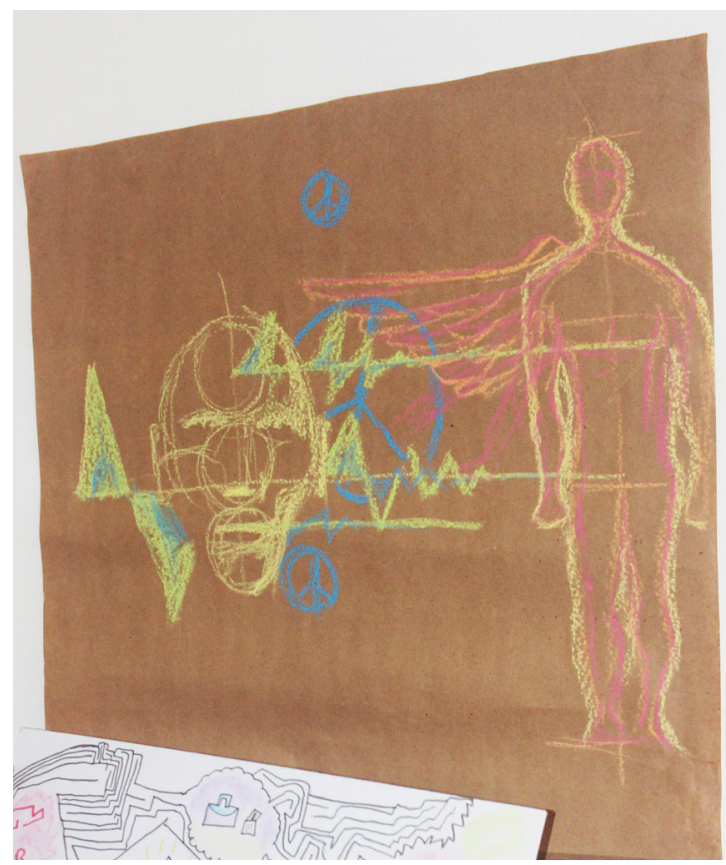

Fuente: elaborado por D, tomado de Molina y Vargas (2017, p. 83)

La excusa del arte es increíblemente buena y útil ... esto me estructura y me hace bien, me permite dejarme una memoria de lo vivido ( $\mathrm{S}$, citado en Molina y Vargas, 2017, p. 161).

... para mí crear algo es muy diferente a solo hablarlo, hay algo concreto de lo que se puede partir o proyectar lo que se siente y piensa". Además, expresa que le parece muy valioso porque son productos que permanecen y se pueden compartir con otras personas (K, citado en Molina y Vargas, 2017, p. 161).

A partir de las sesiones voy "acercándome poco a poco a mayores niveles de concreción" (extracto de mural de evaluación, citado en Molina y Vargas, 2017, p. 187).

De mano con la posibilidad de estructurarse y el efecto de que les implica la materialidad de lo creado, señalaron que el proceso de creación plástica abre una posibilidad de construir y reconstruirse a sí mismas y mismos, a pesar de sus circunstancias de vida y sus condiciones emocionales. En los murales de evaluación refirieron "en la sesión logré comprender que sí puedo recuperarme, repararme" (Mural, sesión V), o los impactos de la 
sesión al señalar: "recordarme que la vida sigue y yo puedo reinventarla" (Mural, sesión VII). Ambas frases refuerzan el criterio de las terapeutas, en tanto el acto creativo abre una vía de reconstrucción de sus subjetividades y les invita a repensar sus vidas al margen de sus progenitores y de sus historias de maltrato.

Por su parte, destacamos el acto creativo como agente movilizador de la pulsión de vida. Los procesos de creación implican un tránsito por lo doloroso, lo oscuro o lo faltante; para luego poder traducirlo en imágenes y crear una obra. Este movimiento implica un pasaje que mueve al sujeto de la pulsión de muerte, a la pulsión de vida; conllevando una activación de procesos de pensamiento, emoción y acción. Los anteriores, son resultado de lo que llamamos: activación de pulsión de vida a través de la creatividad. Por tanto, el encuentro con el color, las texturas y las formas, favorecen un enfrentamiento cara a cara con el impulso creador, que es per se, impulso de vida. Al respecto, los y las participantes externaron lo siguiente: "nuestra creatividad nos puede sacar de estar mal ... -le dice a JPmantenga su creatividad activa para estar bien" (K, citado en Molina y Vargas, 2007, p. 206). $S$ refiere que cuando llegó al grupo estaba en un bache en el que no lograba hacer nada, ahora ha ido dibujando y esto la ha llevado a conocerse mejor y comprender mejor lo que está viviendo, "creo que toda la producción que he hecho acá es muy valiosa" (S, citado en Molina y Vargas, 2007, p. 206).

D expresa que ha redescubierto el dibujo en este proceso, ya que en la carrera no dibuja por placer, sino porque es parte de lo que debe hacer, pero en el proyecto, dibujar le ha hecho sentir paz (Bitácora sesión X). Al respecto, le señala JP "A veces por la condición y síntomas que enfrentamos perdemos el disfrute de la vida, pero D se encuentra en el dibujo" (JP, citado en Molina y Vargas, 2007, p. 206).

En esta misma línea, se destaca el ejemplo de un relato ilustrado que creó una de las participantes (ver figura 4), en el que a través de un personaje referente a ella misma, logra reseñar el paso por el dolor psíquico que implica su condición y el cómo a través de la posibilidad de crear, ella logra sobreponerse y usar su sensibilidad y aprendizajes como motor creativo desde su profesión. Este relato inicia hablando de una niña que no podía dormir, que tenía secretos que le lastimaban y cuyo mundo se había tornado hostil y violento, mientras que cierra hablando de una mujer adulta fortalecida y plena, dedicada al diseño de obras de infraestructura, reseñada de la siguiente forma:

Debido a sus experiencias, Silvido conocía muy bien la fantasía y la importancia de la realidad, ambas presentes en estrecha relación hacían sus obras las preferidas por las personas, y así, Silvido logró encontrar su vocación y más tarde encontró la persona que complementaría todo esto (S, citado en Molina y Vargas, 2017, p. 157). 
Imagen 4. Trabajo libre: Historia de Silvido

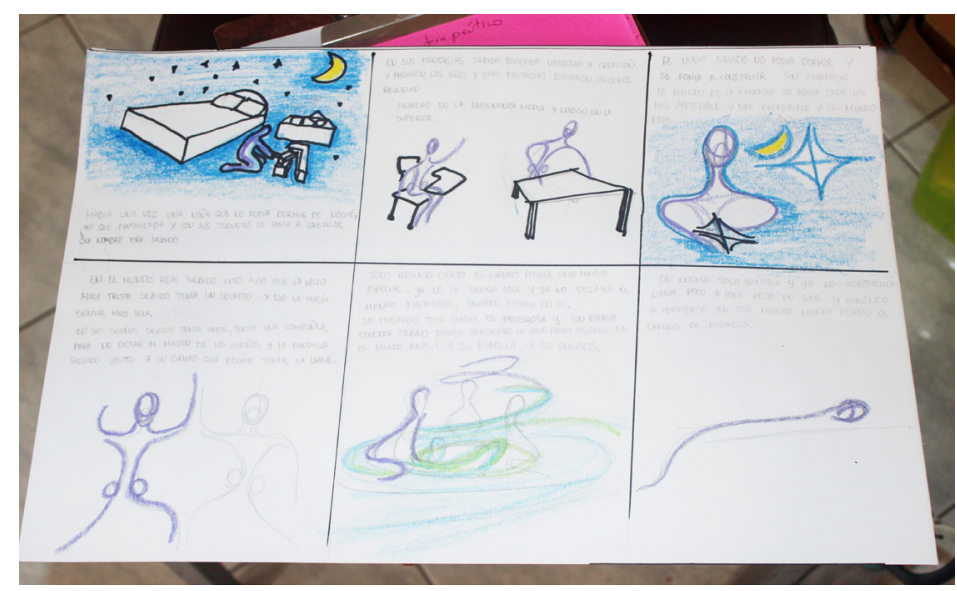

Fuente: elaborado por S, tomado de Molina y Vargas (2017, p. 155)

A partir del trabajo realizado por la joven, se observa cómo, desde su experiencia, la posibilidad de crear obras abre una oportunidad de construir su vida desde un lugar menos doloroso, de integración y sentido para ella, para otras personas y su contexto. Complementariamente, cabe destacar que el acto creativo permitió una reconstrucción subjetiva desde la fantasía, la magia, el juego y la belleza de las palabras. Esta posibilidad de reconstrucción desde el acto creador, tiene un peso simbólico importante, pues no solo permite una reedición del pasado, sino que posibilita vislumbrar un futuro esperanzador con pinceladas de un deseo propio, permitiendo conjugar lo lúdico con lo doloroso, como una oportunidad de construcción, sanación y diversión. En este sentido, compartimos una de las frases más movilizadoras de uno de los participantes, cuando estaba refiriéndose a su experiencia a lo largo del proyecto: "Increíble, mágico, fue una reunión espiritual ... esto trascendió lo científico, lo terapéutico y lo artístico, esto fue algo espiritual. Así es como me siento" (D, citado en Molina y Vargas, 2017, p. 189).

Como último elemento asociado a la activación de la pulsión de vida, se identifica un impacto importante en la reducción de los llamados síntomas negativos en las psicosis, principalmente aquellos asociados con los pensamientos depresivos, apatía, desgano y anhedonia. Según los discursos de los y las participantes y lo registrado en el proceso, el acto creativo provoca una disminución de este tipo de sintomatología, y una activación del impulso de acción. Al respecto, de manera ilustrativa, compartimos dos citas en donde dos participantes nos narran sobre la evolución de sus síntomas. En la sexta sesión, JP refiere las dificultades porque se sentía deprimido y muy cansado, comenta: "en el principio de la sesión me sentía muy mal, pero conforme empecé a esculpir, se me olvidó que me sentía mal y me empecé a sentir bien" (JP, citado en Molina y Vargas, 2017, p. 206).

K refirió una disminución importante en la sintomatología, especialmente los ataques de pánico, y que ha tenido un mejor manejo de la atención y la concentración ( $\mathrm{K}$, citado en Molina y Vargas, 2017, p. 206). Por tanto, a partir de lo anterior, el acto de crear activa un impulso de vida, de acción, a la vez que aporta en la reducción de síntomas asociados a la depresión, anhedonia, apatía, inactividad y ansiedad.

ESCENA. Revista de las artes, 2020, Vol. 79, Núm. 2 (enero-junio), pp. 32-58 


\section{Impacto terapéutico de los procesos grupales}

La consolidación de un proceso terapéutico de naturaleza grupal tiene alcances fundamentales en la creación de un lazo social. Esto, pues el espacio grupal permite el encuentro con un otro especular que experimenta situaciones similares, lo que favorece el reconocimiento de sus historias a través de los relatos de los otros. Este encuentro, a través de las vivencias psicóticas como un lugar común, favoreció la percepción de acompañamiento y de humanización de sus experiencias; moviéndolos del aislamiento, a un lugar común y de compañía. Seguidamente, se ofrecen extractos de aportes de las personas participantes que ilustran este movimiento.

En este proceso yo me di cuenta que hay gente que vive igual que uno y siente igual, escuchar a S con lo del sueño y a todos con cada cosa que viven es muy importante porque veo que no estoy solo. Todos hemos enfrentado muchos problemas. Hallé una guía en este grupo, un apoyo, encontré aceptación. Ha sido un viaje (JP, citado en Molina y Vargas, 20017, p. 202).

El estar en el grupo me ha hecho ver que muchas personas pasan por dificultades como las mías, en la sociedad solo se da una opción para ser normal, pero aquí con ustedes me siento bien (K, citado en Molina y Vargas, 2017, p.202).

El impacto grupal también tuvo su efecto al ocupar un lugar de testigo clave de los procesos creativos, de las obras plásticas y de las narraciones; consolidándose como un público testigo de la palabra y de la creación. Esto facultó que las historias fueran acogidas, contenidas y retroalimentadas; colocándolas en un estatuto de real. Por su parte, el espacio grupal favoreció la apertura de preguntas que promovían el cuestionamiento de los mandatos o prácticas abusivas de las historias familiares, como generadores de una pregunta abierta que buscaba la tachadura de ese Otro feroz, o lo que podría entenderse como una puesta de límites al maltrato físico, emocional y/o sexual que experimentaron en sus historias de vida. Seguidamente, ofrecemos algunos extractos de los relatos más fuertes que escuchamos, sobre cómo las y los jóvenes fueron creando límites al maltrato vivido y construyendo experiencias más amorosas para sí mismas y mismos:

Me tomó 18 años pero finalmente soy solo yo, liberada y sin dolor. Ya ella no tiene poder sobre mí [en referencia a la madre y sus maltratos]. Todavía me cuesta creer que ya todo pasó, voy caminando y me parece mentira que ya todo se haya acabado y que ahora estoy en paz (K, citado en Molina y Vargas, 2017, p. 189).

pero porque sean familia no hay que permitirles todo. No hay que esclavizarse a los valores, hay que cuestionarlo y crear valores propios, destruir los valores impuestos. Yo tengo un deseo de libertad (LA, citado en Molina y Vargas, 2017, p. 205). 
Imagen 5. Trabajo libre: Retrato familiar

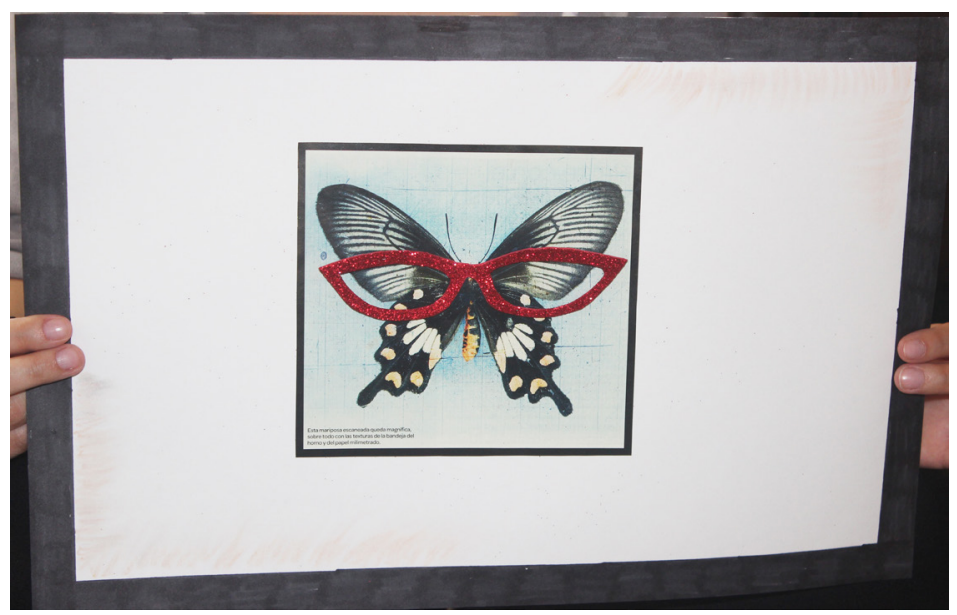

Fuente: elaborado por K, tomado de Molina y Vargas (2017, p. 111)
En uno de los ejemplos citados anteriormente, la joven $\mathrm{K}$ hace referencia a un trabajo (ver figura 5), realizado para retratar a su familia. En éste, realizó un autorretrato representado por una mariposa con lentes, el cual representaba su proceso de transformación (de ahí la mariposa), que le permitía asumirse por cuenta propia y superar una miopía emocional, que no le había permitido dar nombre a esta violencia. Por lo anterior, para retratar a su familia ella decidió autorretratarse, como metáfora de su separación con la familia y la puesta de límite al maltrato.

Asimismo, destacamos la función grupal como vía de fortalecimiento y resarcimiento de narcisismos debilitados. En términos de la validación y reconocimiento constantes de las habilidades o avances de cada uno en un espacio grupal de esta naturaleza. Este rasgo grupal, caracterizado por la solidaridad y respeto por los otros, fue una herramienta fundamental para el fortalecimiento de recursos personales. Finalmente, situamos la importancia del grupo como espacio nutricio y seguro, que ofrece contención para los sujetos. Al respecto, la alimentación física y emocional, el cuido de sus necesidades básicas y emocionales a lo largo del proceso, es un eje sustancial que debe atravesar los procesos de esta naturaleza.

\section{El acto creativo como un recurso para la potencialización de habilidades}

El ejercicio del acto creativo permite el desarrollo e incremento de la creatividad, habilidad intrínsecamente humana, que generalmente sufre bloqueos por las experiencias de vida y procesos educativos tradicionales. La posibilidad de potenciar la creatividad es fundamental, pues es una habilidad que interviene en procesos como: la resolución de problemas y conflictos, la toma de decisiones y el desarrollo de pensamiento crítico, por lo que su desarrollo permite el fortalecimiento de otras habilidades indispensables para su vida.

En este punto es importante destacar, que los objetivos de la arteterapia expresiva parten de la búsqueda del desarrollo de la creatividad y el aumento de la capacidad de autoexpresión. En esta línea, se pudo observar en la evaluación del proyecto, un incremento 

y de atención a la psicosis

en los indicadores explicitados para la categoría llamada "Disposición a la creación", misma que pretendía tener un acercamiento a la evolución de los y las participantes en materia de creatividad y creación. En esta línea, la mayoría de participantes mostraron un aumento en las conductas asociadas a las manifestaciones plásticas de elementos creativos en sus trabajos, así como mayor apertura para la exploración de materiales. Al respecto, quisiéramos retomar dos trabajos de un participante, ya que mostró esta tendencia desde el inicio, pero fue creciendo a lo largo de las sesiones.

Las figuras 6 y 7 muestran dos de los trabajos de M. Su estilo en los trabajos se caracterizó por ser creativo y con gran valor estético. Fueron elaboraciones amplias, que siempre se desbordaban del soporte utilizado y con una tendencia a saturar las obras de elementos, en los cuales no quedara ningún espacio vacío. Tendió a utilizar materiales de diversas texturas y colores, tales como: pinturas, telas, cintas, papeles, plumas, recortes, paletas, plastilina y arcilla. Incluyó elementos poco convencionales como arena, aserrín o velas derretidas, elementos que sus compañeros nunca incluyeron en sus trabajos. Cabe señalar que fue el participante que tendió a utilizar mayor diversidad y cantidad de materiales, mostrando iniciativa para la exploración

Imagen 6. Trabajo libre: lo que aún causa dolor y logros alcanzados

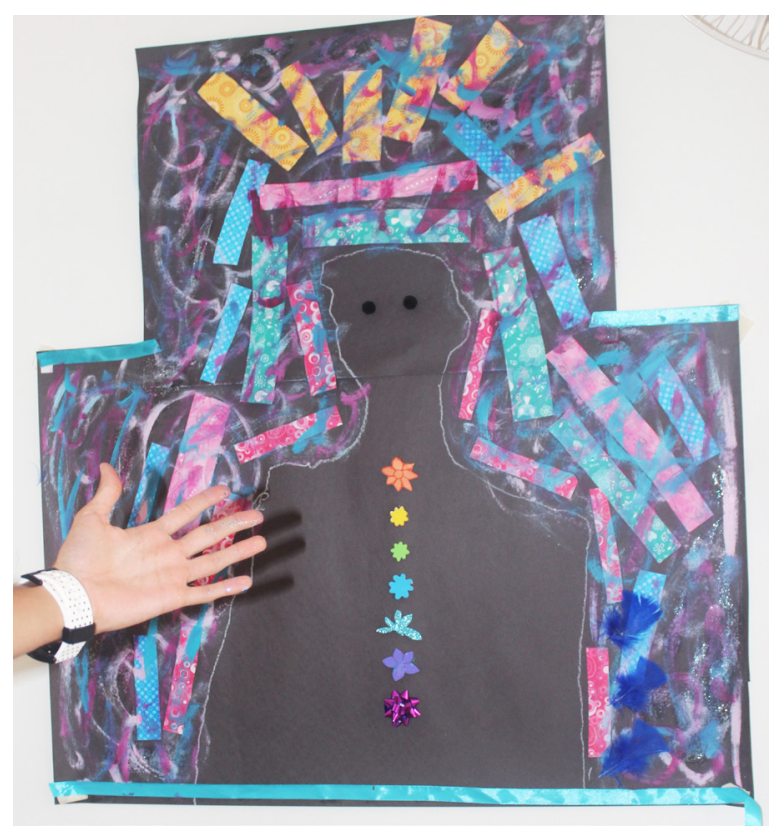

Fuente: elaborado por M, tomado de Molina y $\operatorname{Vargas}(2017$, p. 131) y el uso creativo de los mismos. En las creaciones de este joven, siempre sobresalieron elementos correspondientes a su autoimagen e inclusión de elementos espirituales. La imagen de la figura 6 es una muestra de su trabajo, en la cual representó su autoimagen con sus chacras y su aura. Realizó una mezcla de diversos materiales, texturas y colores.

En cuanto a la figura 7, el participante elaboró una estructura en 3D alusiva a una escoba, la cual utilizó como metáfora de un medio de transporte que le ayudará a cumplir sus sueños. Alrededor de esta, construyó una explicación de su significado. Llamó la atención, que con los mismos materiales que se venía trabajando él logró salirse de las elaboraciones planas y creó una estructura tridimensional, con gran valor creativo y con mezcla de materiales como madera, hojas, arcilla, cintas y pintura. 
Imagen 7. Los anhelos y los sueños

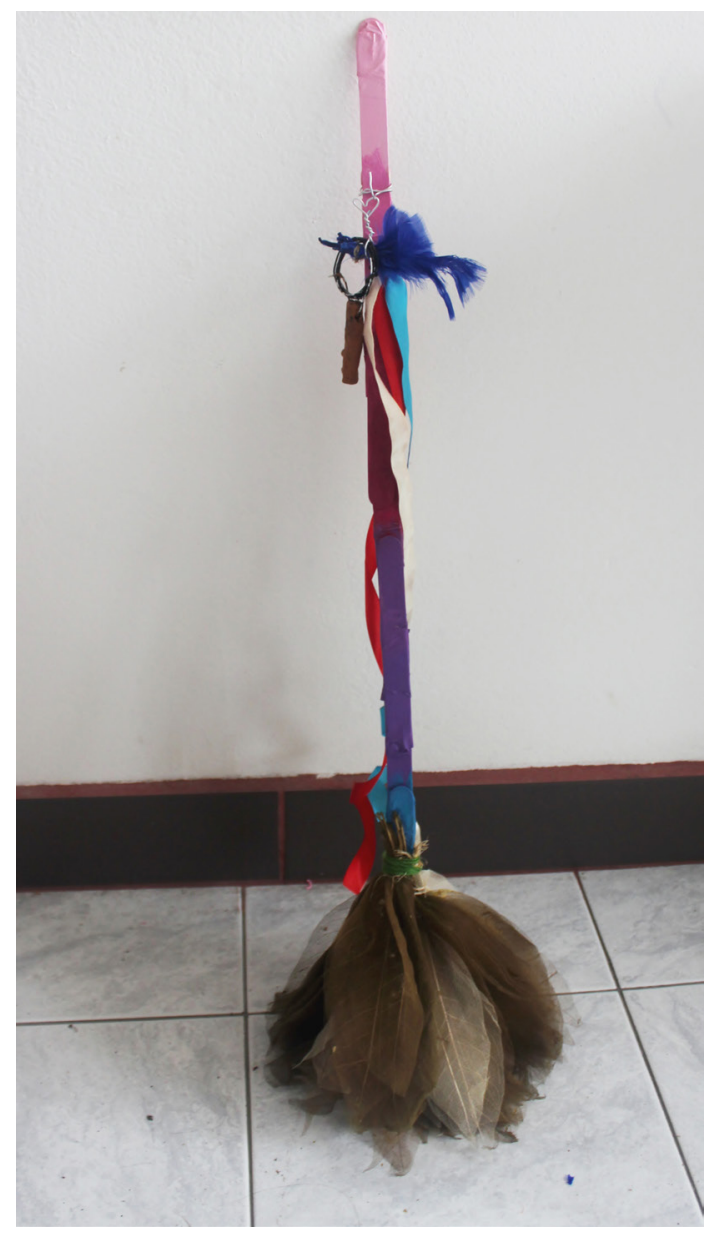

Fuente: elaborado por M, tomado de Molina y Vargas (2017, p. 133)
En torno al fortalecimiento de la expresividad emocional y de pensamientos, en términos generales se identificó una ampliación en la autoexpresión de los y las participantes. No obstante, quisiéramos destacar el caso de LA, quien, por las características de su condición, mostraba inicialmente serias dificultades para comunicarse, para establecer contacto visual, físico y verbal y con demostraciones de displacer al interactuar en el grupo.

Conforme el proceso fue avanzando se fue identificando mayores de niveles de expresión e intercambio con sus compañeros, en las últimas sesiones a LA se le escuchó compartir sus opiniones con respecto a diversos temas comentados en el grupo durante las actividades, y participó de manera más activa en los espacios abiertos del grupo en la parte final de cada sesión. En la figura 8, se presenta uno de los trabajos del joven. Si bien, mostró cierta dificultad para explorar materiales y mostró preferencia por los trabajos tipo collage, destacamos la posibilidad que le dio la producción creativa para poder expresarse. La producción emocional alrededor de estos trabajos fue realmente valiosa, en términos del avance que implicó para el joven.

Respecto a la Figura 8, el joven logró externar situaciones familiares que le han generado mucho dolor y conflicto, principalmente con su hermano menor y su padre. En ese retrato logra describir a su padre como una persona con rasgos muy fuertes y rígidos, asociada a la imagen de un dictador. Hizo referencia a sentimientos de culpa y persecución; mientras que a la madre, la refiere como más cercana y cálida (imágenes del centro). Al hermano no lo incluyó en el trabajo, como un reflejo de su lejanía vincular.

A través del proceso de creación, el joven logró hacerse preguntas sobre los mandatos paternos: "estoy poniéndolo en entredicho", "estoy cuestionando su moral" (LA, citado en Molina y Vargas, 2007, p. 164). En este sentido, se observó un avance relacionado con 
Imagen 8. Retrato Familiar

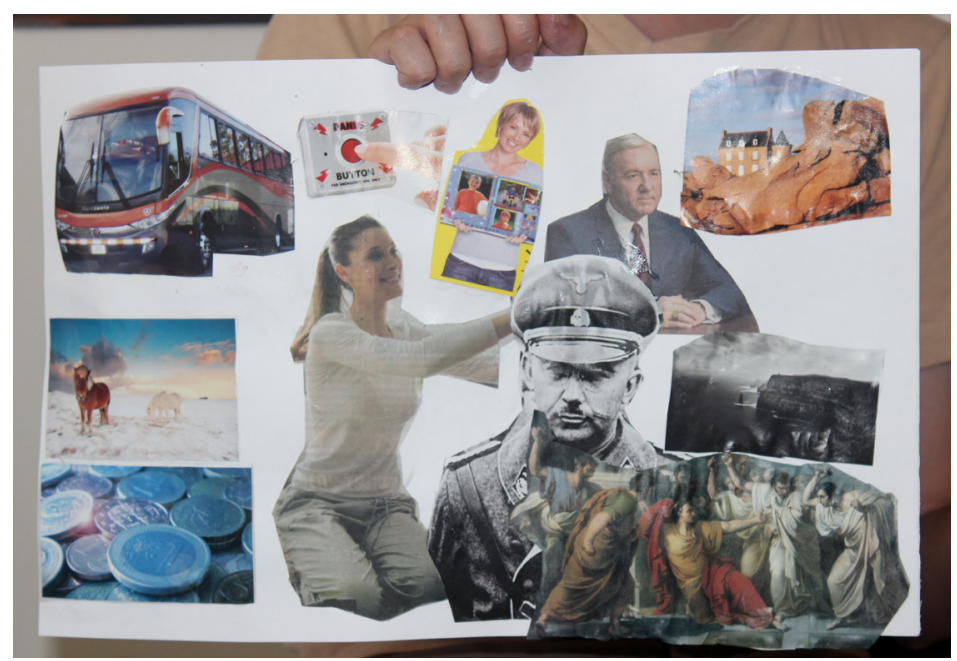

Fuente: elaborado por LA, tomado de Molina y Vargas (2017, p.163) lograr simbolizar el maltrato que ha ejercido su padre sobre él, a partir de la exigencia de mandatos morales sumamente rígidos, que han sido vividos por el joven como una prisión y son fuente de angustia y sufrimiento. Lo anterior, a su vez, da pie al inicio de dos procesos muy importantes: el camino para simbolizar e incluir en su historia el maltrato paterno y los efectos de éste en su subjetividad (Kolko, 2001), y comenzar a tachar ese Otro voraz, que lo persigue desde los absolutos de la moral.

Finalmente, nos resulta fundamental señalar, que al igual que otras de las personas participantes, LA vivió una mejora en su posibilidad de establecimiento de lazo social, lo que se evidenció en su aumento en la disposición y frecuencia de contacto con las demás personas participantes, incluyendo al equipo terapéutico. Esto se considera fundamental en el proceso de mejoría de la condición emocional del joven, ya que la experiencia de su dolor psíquico se ha visto atravesada, frecuentemente por el aislamiento, ante lo que el contacto con el otro resulta difícil y generador de angustia.

\section{Reflexiones finales}

Durante el tránsito por la experiencia del proyecto y el análisis de los beneficios de éste, se rescatan las siguientes reflexiones: el rol de las terapeutas en procesos que impliquen el acto creativo como una vía de atención psicoterapeútica, y sobre la relevancia que tiene la inclusión de espacios arteterapéuticos grupales, para la atención de la salud emocional de distintas poblaciones que enfrenten condiciones asociadas a la psicosis.

En cuanto al rol del terapeuta, se identifica que debe prevalecer un posicionamiento marcado por la flexibilidad, respeto, escucha y actitud lúdica. Un trabajo terapéutico que utilice al acto creativo como vía de mediación terapéutica, con una población con las características ya señaladas, requiere de la figura del o la terapeuta un cuestionamiento de su rol más tradicional, en donde se caracterice por la horizontalidad y el acompañamiento constante, que tenga claridad de su papel como testigo de los procesos, facilitador del tejido de puentes significantes, y en donde, la interpretación directa de las creaciones no tiene lugar. 
Además, se debe estar en la capacidad de construir un proceso terapéutico, pero también ir trazando los límites y preparando los cierres.

Como segundo elemento, se destaca la importancia de la inclusión de procesos que impliquen el acto creativo, como una vía de atención a la salud mental en nuestros sistemas de salud costarricenses, trascendiendo incluso las fronteras de la Universidad de Costa Rica, casa de nuestro proyecto, y ampliándose a diversos centros de salud. La necesidad de inclusión de otras vías de atención emocional de personas con diagnósticos asociados a la psicosis, en los sistemas de salud, se valora como pertinente por varios motivos. El primero de ellos, corresponde a que espacios grupales que se encuentren abiertos a la creatividad y la creación, como vías para la atención de las experiencias subjetivas, abre posibilidades para que surjan lugares de encuentro, que permitan la creación del lazo social entre sus participantes, como alternativa al aislamiento en el que viven las personas con diagnósticos como los ya descritos. Además, estas propuestas, al no estar centradas en el diagnóstico, sino en sus potencialidades para la creación y la expresión, ofrece una posibilidad de despatologizar estas condiciones emocionales, y abordarles desde nuevas aristas.

También, en estos proyectos, al no ser el punto de referencia la estética ni la técnica, sino la movilización emocional a través del acto creativo, el arte y la posibilidad de crear se democratizan, y dejan de ser territorios exclusivos para determinados sectores sociales. Finalmente, consideramos que propuestas de la línea de nuestro proyecto, se enfocan en la potencialización de los recursos de las personas, sus habilidades, deseos y necesidades, y con ello, se fundamentan en una práctica que apuesta a la vida, más allá del sufrimiento vivido, es decir hacia una transformación a partir de la creación.

\section{Referencias}

Coll, F. (2004). Recursos de arteterapia en el aula escolar. En Pilar María Domínguez Toscano (coord.), Arteterapia. Nuevos Caminos para la mejora personal y social, pp 11-21. España: Consejería de Innovación, Ciencia y Empresa de la Junta de Andalucía y Fondo Social Europeo.

Domínguez, P. (2004) Arteterapia. Nuevos Caminos para la mejora personal y social. España: Consejería de Innovación, Ciencia y Empresa de la Junta de Andalucía y Fondo Social Europeo.

Kolko, C. (2001). Los ausentes de la memoria, figuras de lo impensado. Argentina: Homo Sapiens Ediciones.

Marini, M. (1989). Lacan: itinerario de su obra. Argentina: Ediciones Buenos Aires / Nueva Visión.

Martínez, N. (2004). La formación del arteterapeuta en España y Europa. En Pilar María

ESCENA. Revista de las artes, 2020, Vol. 79, Núm. 2 (enero-junio), pp. 32-58 
El acto de crear, una ruta de acercamiento al psiquismo humano

Artículos y de atención a la psicosis

Domínguez Toscano (coord.), Arteterapia. Nuevos Caminos para la mejora personal y social. pp 37-57 España: Consejería de Innovación, Ciencia y Empresa de la Junta de Andalucía y Fondo Social Europeo.

Marxen, E. (2011). Diálogos entre arte y terapia: del arte psicótico al desarrollo de la arteterapia y sus aplicaciones. España: Gedisa.

Molina, N. \& Vargas, P. (2007). Una experiencia arteterapéutica con estudiantes de la Universidad de Costa Rica: Diálogos entre la arteterapia, el psicoanálisis y las psicosis. Tesis para optar por el grado de Maestría en Psicología Clínica y de la Salud. Universidad de Costa Rica.

Polo, L. (2000). Tres aproximaciones al arte terapia. Arte, Individuo y Sociedad. (12), 311-319. Recuperado de https://revistas.ucm.es/index.php/ARIS/article/view/ARIS0000110311A/5934

Rodríguez, J. \& Troll, G. (2004). La arteterapia. Prácticas, técnicas y conceptos. París: Ellèbore.

Van Gogh, V. (2003). Cartas a Théo. Barcelona: Idea Universitaria.

ESCENA. Revista de las artes, 2020, Vol. 79, Núm. 2 (enero-junio), pp. 32-58 